\title{
Effect of 4-Pentenoate on Rat Liver Ornithine Transcarbamylase
}

\author{
ALLEN M. GLASGOW(7) \\ Children's Hospital National Medical Center, Washington, D.C., USA
}

\begin{abstract}
Summary
The effect of 4-pentenoate on rat liver ornithine transcarbamylase was studied. No efiect was found. It is concluded that the efiect of 4-pentenoic acid on ornithine transcarbamylase reported by others was probably due to technical errors. Available evidence indicates that 4-pentenoate inhibits ureagenesis by interfering with mitochondrial energy metabolism, which in turn impairs mitochondrial ornithine transport or depletes mitochondrial ATP, impairing carbamyl phosphate synthesis, or both.
\end{abstract}

\section{Speculation}

Reported kinetic abnormalities of ornithine transcarbamylase in Reye's syndrome may be due to technical error.

It has recently been reported that 4-pentenoic acid reduces the activity of carbamyl phosphate synthetase (CPS) and reduces the $V_{\max }$ and lowers the $K_{m}$ for carbamyl phosphate of ornithine transcarbamylase (OTC) (4). These effects were noted only after preincubation -of the enzyme with 4-pentenoic acid. Evidence has been presented that 4-pentenoate inhibits mitochondrial citrulline synthesis by interfering with mitochondrial energy metabolism, which in turn impairs mitochondrial ornithine transport or depletes mitochondrial ATP, impairing carbamyl phosphate synthesis, or both (2). Although these studies are not in direct conflict (different types of experiments were done), they do suggest entirely different mechanisms of inhibition of ureagensis by 4-pentenoic acid. Therefore, we have re-examined the effect of 4-pentenoic acid on ornithine transcarbamylase from rat liver.

\section{METHODS}

Livers were obtained from adult male Sprague/Dawley rats maintained on a commercial chow and killed by a blow to the head. The assay for OTC was as described by Snodgrass (5) with the following exceptions. Ferric sulfate (equivalent in ferric ions) was used instead of ferric ammonium sulfate. The reaction was stopped with $5 \%$ trichloroacetic acid instead of $0.5 \%$ phosphotungstic acid in $5 \%$ trichloroacetic acid and the mixture was not centrifuged since the amount of protein was so small that no precipitate formed (this small amount of protein had no effect on a citrulline standard curve). A blank consisting of a homogenate heated at $100^{\circ}$ for 10 min was always included.

4-Pentenoate was purified as previously described (3) and was always added as the $\mathrm{Na}$ salt at $\mathrm{pH} 7.4 \pm 0.1$.

\section{EXPERIMENT 1}

This experiment was designed to be similar to that performed by Sinatra et al. (4). A 1:200 homogenate of rat liver in 5\% (V/ V) glycerol $1 \mathrm{mM}$ EDTA- $\mathrm{Na}_{4}$ salt and $10 \%(\mathrm{v} / \mathrm{v})$ dimethyl sulfoxide was mixed with an equal volume of either $\mathrm{H}_{2} \mathrm{O}$ or 24 $\mathrm{mM}$ 4-pentenoate. Both mixtures were incubated at $37^{\circ}$ for 30 min (the times of the preincubations referred to here and below are not exact but are minimums because it took several minutes to add the preincubated homogenate to the assay medium and to start the assay). OTC was assayed using $50 \mu \mathrm{l}$ preincubated homogenate in a final volume of $0.6 \mathrm{ml}$ containing $10 \mathrm{mM}$ ornithine, $0.15 \mathrm{M}$ Tris- $\mathrm{HCl}, \mathrm{pH} 7.0$, and $0.25 \mathrm{mM}$ to $5.0 \mathrm{mM}$ carbamyl phosphate incubated at $37^{\circ}$ for $10 \mathrm{~min}$.

\section{EXPERIMENT 2}

Mitochondria prepared as previously described (2) were incubated for $30 \mathrm{~min}$ at $37^{\circ}$ under air in $15 \mathrm{mM} \mathrm{KCl}-2 \mathrm{mM}$ EDTA-5 $\mathrm{mM} \mathrm{MgCl}-50 \mathrm{mM}$ Tris- $\mathrm{HCl}-4 \mathrm{mM}$ K-phosphate- $25 \mathrm{mM}$ sucrose$10 \mathrm{mM}$ glutamate, at a final $\mathrm{pH}$ of 7.4 (This is the same medium used to show inhibition of mitochondrial citrulline synthesis by 4-pentenoate except that the substrates for citrulline synthesis were omitted (2). 4-Pentenoate was present during the preincubation at concentrations of $0,1,5$, and $25 \mathrm{mM}$. During this preincubation each flask contained $2.2 \mathrm{mg}$ protein in $1 \mathrm{ml}$ medium. After the preincubation the mitochondria were diluted $1: 25$ with $\mathrm{H}_{2} \mathrm{O}$. OTC was assayed using $100 \mu$ l homogenate in a final volume of $0.6 \mathrm{ml}$ containing $10 \mathrm{mM}$ ornithine, $0.2 \mathrm{M}$ malate, $\mathrm{pH} 7.0$, and from $0.25 \mathrm{mM}$ to $5.0 \mathrm{mM}$ carbamyl phosphate incubated at $37^{\circ}$ for $10 \mathrm{~min}$.

\section{EXPERIMENT 3}

A 1:5000 homogenate of liver in $\mathrm{H}_{2} \mathrm{O}$ was incubated 30 min at $37^{\circ}$ either with or without $1 \mathrm{mM}$ 4-pentenoate. Then OTC was assayed in duplicate exactly as described in Experiment 2 using $100 \mu \mathrm{l}$ homogenate with carbamyl phosphate varied from 0.5 to $5 \mathrm{mM}$.

Protein was determined with the biuret reaction after removing lipid (1) with bovine serum albumin as standard.

\section{RESULTS}

Shown in Figure 1 are the results of the experiment similar to that done by Sinatra et al. (4). 4-Pentenoate at a concentration of $12 \mathrm{mM}$ during the preincubation and $1 \mathrm{mM}$ during the OTC assay had no appreciable effect on the amount of citrulline formed at any concentration of carbamyl phosphate. It is noteworthy that at $0.25 \mathrm{mM}$ carbamyl phosphate about $60 \%$ of the carbamyl phosphate was consumed, thus this data cannot be used to calculate a $\mathrm{K}_{\mathrm{m}}$. At $5 \mathrm{mM}$ carbamyl phosphate only about $6 \%$ of substrate was consumed, so the data at this point is a fair reflection of enzyme activity and there was no apparent effect of 4-pentenoate.

The effect of preincubating mitochondria with various concentrations of 4-pentenoate on OTC subsequently assayed in mitochondrial homogenates is shown in Figure 2. 4-Pentenoate had no effect on OTC activity. In this experiment about $30 \%$ of the substrate was consumed at $0.25 \mathrm{mM}$ carbamyl phosphate.

The effect of incubating a 1:5000 aqueous homogenate with and without $1 \mathrm{mM}$ pentenoate is shown in Figure 3 as a double recipical plot. In this experiment no more than 5-6\% of the substrate was consumed at any concentration of carbamyl phos- 


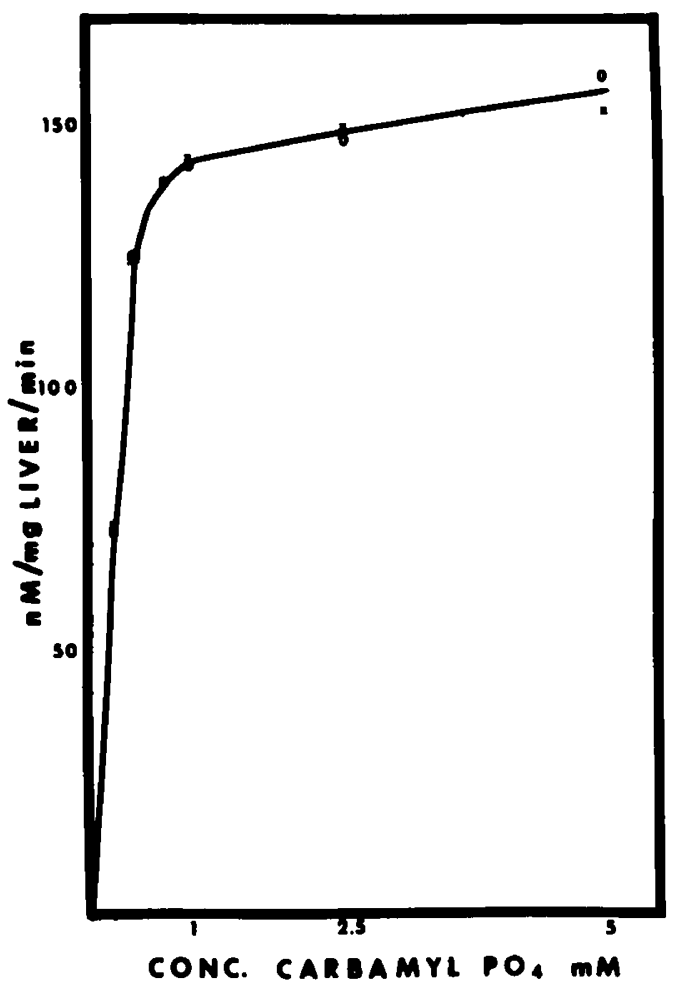

Fig. 1. Effect of 4-pentenoate on rat liver ornithine transcarbamylase. Preincubation was with no $(O)$ or $12 \mathrm{mM}$ pentenoate $(x)$. Experimental details are given in under "Methods."

phate. If anything, the OTC activity was increased in the homogenate incubated with $1 \mathrm{mM}$ 4-pentenoate. There was no apparent effect on the $K_{m}$ for carbamyl phosphate, which was about $0.75 \mathrm{mM}$.

\section{DISCUSSION}

In this study it was not possible to measure the $\mathrm{K}_{\mathrm{m}}$ for carbamyl phosphate of OTC using conditions similar to those used by Sinatra et al. (4) because so much substrate was consumed. This was the case even though the homogenate was diluted somewhat more during the OTC assay and somewhat less time was used for the incubation.

If we assume a liver protein concentration of $20 \%$ it is possible to calculate the percentage of substrate consumed in the experiment reported in Figure 3 of the report of Sinatra et al. (4). At $0.25 \mathrm{mM}$ carbamyl phosphate each tube in their study contained $125 \mathrm{nmol}$ carbamyl phosphate $(0.25 \mathrm{mM} \times 0.5 \mathrm{ml})$. If it is assumed this experiment was done with a $0.5 \%$ homogenate which was diluted with an equal volume of water or 4-pentenoic acid, then $50 \mu$ l of diluted homogenate would contain $0.125 \mathrm{mg}$ liver $\left(0.25 \mathrm{mg} / 100 \mathrm{ml} \times 5 \times 10^{-4} 100 \mathrm{ml} / 50 \mu \mathrm{l}\right)$ or $0.025 \mathrm{mg}$ protein $(0.125 \times 20 \%)$. Reading from their Figure 3 we find that at $0.25 \mathrm{mM}$ carbamyl phosphate $220 \mathrm{nmol}$ citrulline $/ \mathrm{mg}$ protein/min were produced. Thus, during the $15-\mathrm{min}$ incubation, $3,300 \mathrm{nmol} / \mathrm{mg}$ protein were produced. In the tube containing $0.025 \mathrm{mg}$ protein, $82.5(3,300 \times 0.025)$ citrulline was produced. Thus a little more than one-half of the carbamyl phosphate was consumed. This makes impcssible any measurement of the $K_{m}$ for carbamyl phosphate of OTC from their data.

Sinatra et al. (4) also found that preincubation of homogenates with 4-pentenoic acid reduces OTC activity. This effect was not found in the present study. Apparently they incubated homogenates with 4-pentenoic acid (they did not specify otherwise), whereas in the study 4-pentenoate was used. Snodgrass (5) has shown that incubating OTC at $\mathrm{pH} 5.8$ for $15 \mathrm{~min}$ results in a

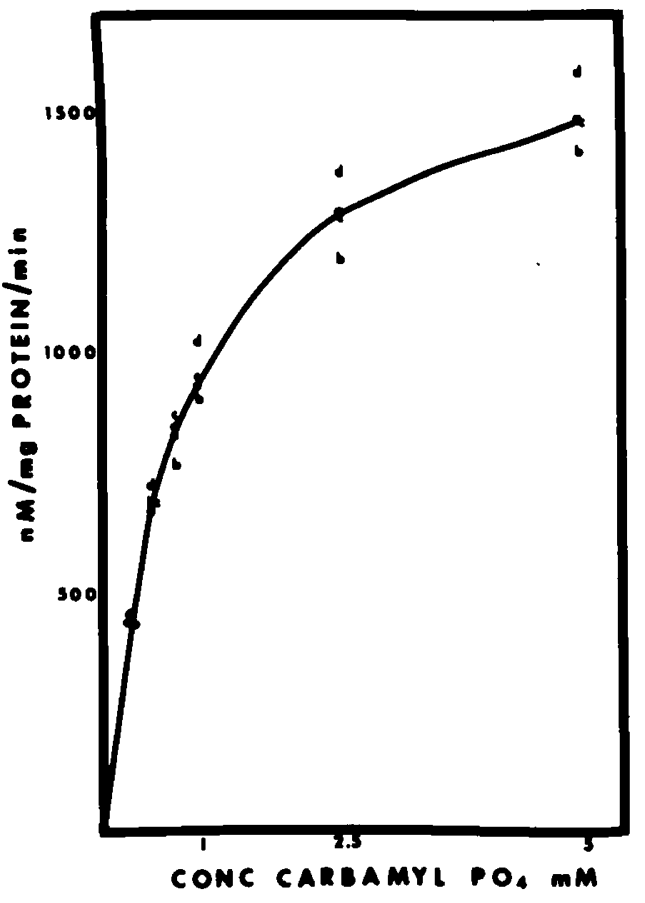

Fig. 2. Effect of incubating rat liver mitochondria with 4-pentenoate on ornithine transcarbamylase. Mitochondria were preincubated with no (a), $1 \mathrm{mM}(b), 5 \mathrm{mM}(c), 25 \mathrm{mM}(d)$ 4-pentenoate. Experimental details are given under "Methods."

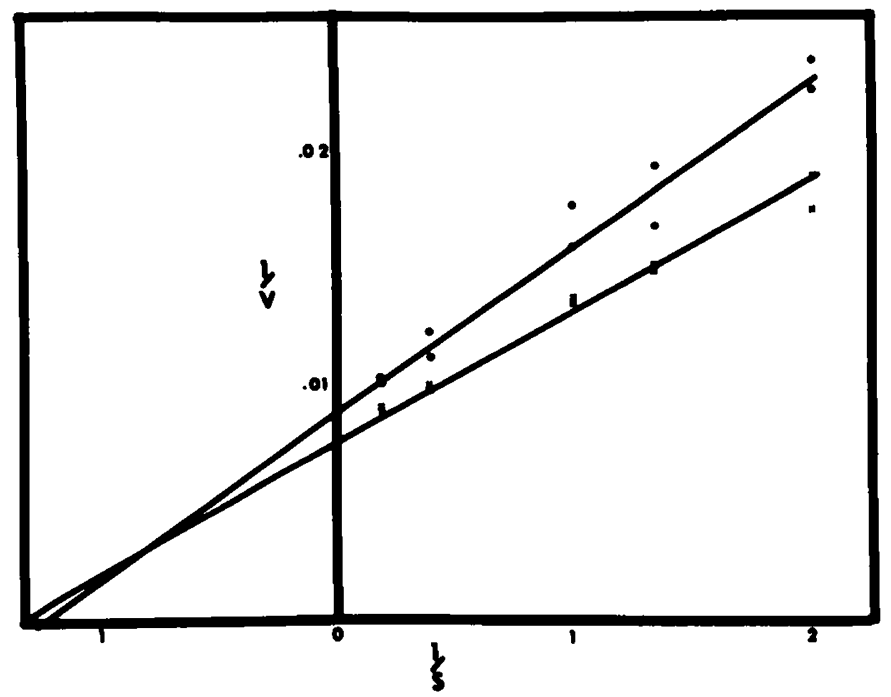

Fig. 3. Effect of 4-pentenoate on the $K$ for carbamyl phosphate of ornithine transcarbamylase. Homogenates were preincubated with no $(O)$ or $1 \mathrm{mM}$ 4-pentenoate $(x)$. I/V units are $\mathrm{nmol} / \mathrm{mg} \mathrm{liver} / \mathrm{min}^{-1} . \mathrm{I} / \mathrm{S}$ units are $\mathrm{mM}^{-1}$. Lines were drawn by visual inspection. Experimental details are given under "Methods."

reduction of OTC activity to $57 \%$ of control. When an homogenate similar to the one used by Sinatra et al. (4) was mixed with an equal volume of $2 \mathrm{mM}$ 2-pentenoic acid (which should be similar to 4-pentenoic acid), a pH of 5.3 was obtained. Thus the difference in the effect of 4-pentenoic acid on OTC activity in the study of Sinatra et al (4) and in the present study may be due to differences in the $\mathrm{pH}$ of the preincubation medium.

There remains the question: "Does 4-pentenoate or a metabolite inhibit OTC?" It seems clear that 4-pentenoate does not. The possibility that a metabolite of 4-pentenoate inhibits OTC has not been totally excluded. It is possible for example that a 
metabolite such as 4-pentenoyl-CoA would be limited by the amount of CoA present in the liver. Since the liver extract has to be so diluted in the final assay for OTC, there might not be enough $\mathrm{CoA}$ to form inhibitory concentrations of pentenoyl$\mathrm{CoA}$. Thus, the experiments reported here might not have detected a reversable inhibition, but should have detected a nonreversable inhibition of OTC by a metabolite of 4-pentenoate.

On the other hand, it has been shown that both succinate and oligomycin plus dinitrophenol (which makes exogenous ATP available) totally reverse the inhibition of mitochondrial citrulline synthesis caused by 4-pentenoate (2). It seems unlikely that these compounds would reverse a direct enzyme inhibition. (We would like to interject a hope for extreme caution in any attempt to apply this reversal by succinate to the clinical situation of Reye's syndrome.)

Finally, the deficiencies in the assay methods used by Sinatra et al. (4) (and by Thaler et al. (6), since they used essentially the same assay) make it difficult to evaluate abnormalities of OTC reported in patients with Reye's syndrome. Apparently OTC activity is reduced in Reye's syndrome but the reported kinetic abnormalties are in question. In these studies it should be noted that it is not so much the results for patients with Reye's syndrome that are in error (although some probably are), but the results for controls that are in error.

\section{CONCLUSION}

No effect of 4-pentenoate on rat liver ornithine transcarbamylase was demonstrated in this study. It is concluded that technical errors caused other investigators to conclude that a metabolite of 4-pentenoic acid inhibits ornithine transcarbamylase.

\section{REFERENCES AND NOTES}

1. Cleland K. W., and Slater, E. C.: Respiratory granules of heart muscle. Biochem. J. 53: 547 (1973).

2. Glasgow, A. M., and Chase, H. P.: Effect of pent-4-enoic acid, propionic acid and other short-chain fatty acids on citrulline synthesis in rat liver mitochondria. Biochem J., 156: 301 (1976).

3. Glasgow, A. M., and Chase, H. P.: Production of the features of Reye's syndrome in rats with 4-pentenoic acid. Pediat. Res., 9: 133 (1975)

4. Sinatra, F., Yoshida, T., Applebaum, M., Mason, W., Hoogenraad, N. J. and Sunshine, P.: Abnormalities of carbamyl phosphate synthetase and ornithine transcarbamylase in liver of patients with Reye's syndrome. Pediat. Res., 9: 829 (1975).

5. Snodgrass, P. J.: The effects of $\mathrm{pH}$ on the kinetics of human liver ornithinecarbamyl phosphate transferase. Biochemistry, 7: 3047 (1968).

6. Thaler, M. M., Hoogenraad, N. J., and Boswell, M.: Reye's syndrome due to novel protein-tolerant variant of ornithine transcarbamylase deficiency. Lancet, ii: 438 (1974)

7. Requests for reprints should be addressed to: A. M. Glasgow, M.D., Chiłdren's Hospital National Medical Center, 2125 13th St. N.W., Washington, D.C. 20009 (USA).

8. Received for publication March 3, 1976

9. Accepted for publication September 9, 1976.

$\begin{array}{ll}\text { DNA } & \text { lung } \\ \text { embryo, chick } & \text { Pneumocystis carinii } \\ \text { epithelial lung cells } & \text { RNA }\end{array}$

\title{
Propagation of Pneumocystis carinii in Vitro
}

\author{
LINDA L. PIFER, WALTER T. HUGHES, ${ }^{(55)}$ AND MARTIN J. MURPHY, JR.
}

Infectious Diseases Service, St. Jude Children's Research Hospital, Memphis, Tennessee, USA

\begin{abstract}
Summary
Pneumocystis carinii was propagated in vitro with primary embryonic chick epithelial lung (CEL) cells. Viability and growth of the organism were demonstrated by direct observation of the reproductive cycle in the Sykes-Moore chamber, serial passage with an increase in the number of mature cyst forms, the cytopathic effect of the organism on cell culture, and inhibition of growth of the organism by specific antiserum and pentamidine isethionate. Attempts to culture $P$. carinii indefinitely were not successful. However, cyst forms derived from murine and human sources increased 100-fold and 10-fold, respectively, during CEL cell culture passages. Serial passage of trophozoites alone resulted in the development of typical CPE and a maximum number of $2.8 \times 10^{3}$ cyst forms. Autoradiographic methods demonstrated active DNA, RNA, and protein synthesis within the cyst and suggest that metabolic interaction between the host cells and the organisms occurred. The nature of the attachment of $P$. carinii to the host CEL cell was clearly discernible by scanning electron microscopy (SEM).

In the reproductive cycle a vegetative cell (designated "trophozoite") attached by tubular expansions to the host CEL cell, probably for the transport of essential nutrients, and then de-
\end{abstract}

tached without entering the cell. Sporozoites developed within the detached young cyst, reaching a maximum number of eight within the mature cyst. Excystment occurred through single or multiple sites in the cyst wall, after which the released trophozoite attached to a new host cell.

\section{Speculation}

The in vitro propagation of $P$. carinii provides a basis for further studies to characterize the biologic and biochemical features of this organism and a source of antigen for the development of serologic tests for specific antibody by which the epidemiology and spectrum of clinical disease can be delineated more clearly.

$P$. carinii is a cause of diffuse alveolar disease and interstitial plasma cell pneumonitis (36). Latent infection may occur in the lungs of man and lower animals. Active pneumonitis can be provoked by immunodeficient states or immunosuppressive therapy (18).

This organism was first described in 1909 by Chagas from light microscopic observations of guinea pig lungs infected with Try- 